\title{
The Relationship Between Loneliness and Problematic Internet Use Among Young Adults Who Are Social Media Users
}

\author{
Cathlinszky Zea Harlendea ${ }^{1}$ Sandi Kartasasmita ${ }^{1 *}$
}

\author{
${ }^{1}$ Faculty of Psychology, Universitas Tarumanagara, West Jakarta 11440, Indonesia \\ *Corresponding author. Email: sandik@fpsi.untar.ac.id
}

\begin{abstract}
This research aimed to test relationship between loneliness with problematic internet use in young adults who are social media users. When the individual's expectations for relationships with others are not consistent with reality, the individual will experience loneliness. The internet is one of the ways to have a social interaction and reduce feelings of loneliness. Feeling comfortable using internet for social interaction is a characteristic of individuals with problematic internet use. This research is a quantitative research with correlation techniques. Participants in this research were 508 young adults aged 18-40 years consisting of 133 men and 375 women in Indonesia. This research uses the Generalized Problematic Internet Use Scale 2 which was arranged by Reinaldo \& Sokang (2016) and UCLA Loneliness Scale Version 3 which was arranged by Fatriani (2019). Hypothesis test results using Pearson Correlation showed $\mathrm{r}(508)=0.432, \mathrm{p}=0.000<0.05$. These results indicate that there is a significant and positive relationship between loneliness with problematic internet use in young adults who are social media users.
\end{abstract}

\section{Keywords: Loneliness, problematic internet use, young adults}

\section{INTRODUCTION}

Internet today has become a daily use for human beings. Therefore, the internet can develop rapidly and can be used by people of all ages. There are many uses of the internet such as playing game online, listening to music, and also social media. Montag et al. [1] states that the use of the internet especially social media has a strong relationship with Problematic Internet Use (PIU).

PIU is difficulties that individuals experience in managing life when they are not using the internet which involves emotional symptoms, behavior, as well cognitive (Caplan et al.) [2]. PIU often found in young adults. This can be explained by Reinaldo \& Sokang [3] stated that students aged 21 to 26 years who are included in the young adult tend to have difficulty managing behavior in using the internet and have the urge to be online all the time. Many factors can cause PIU in young adults.

Factors that cause PIU include poor family function, lack of time spent with family, and loneliness (Costa et al.) [4]. In addition, Turkle [5] in his book states that the internet and social media are contributing to the increase of loneliness because it replaces face-to-face interaction face-to-face with online social interaction. According to Costa et al. [4] individuals who experience loneliness prefer to make social interaction and as a way of reducing feeling loneliness by using the internet.
Loneliness itself can be defined as negative emotions in individuals which comes from an imbalance between social relationships with other people in quantity and quality which is expected with what occurs in the individual's life (Russell, Peplau and Cutrona) [6]. Young adults have a tendency to experience higher loneliness than other adults. This is based on the research conducted by Peltzer and Pengpid [7] who conducted research in Indonesia regarding loneliness found that the highest level of loneliness at Indonesia is one of them in the young adults. That facts can be explained by Arnett in Santrock [8] reveals that one of the characteristics of the early adulthood when individuals start exploring identity as well as starting relationships with the opposite sex. Erikson's development stage theory also states that young adults are on intimacy vs. isolation which the tasks are finding and choosing friends and making a more intimate relationship (Papalia) [9]. Young adults are the age range from 18 years until 40 years (Santrock) [8]. Several previous studies found several differences regarding the relationship between loneliness and the Problematic Internet Use. In a study conducted by Costa et al. [4] found that loneliness has a significant relationship with Problematic Internet Use (PIU). Research conducted by Blachnio et al. [10] also found that the relationship between loneliness and PIU is consistently positive. However, there are contrasting differences based on the results of research by Andangsari \& Dhowi [11] that there 
was no significant relationship between loneliness and PIU, especially for adults in Indonesia.

\subsection{Our Contribution}

The results of this study are expected to be theoretically useful for psychology especially in the field of social psychology and clinical psychology as well increase knowledge and insight about the relationship between loneliness and problematic internet use in young adults who are social media users. This research also expected to help young adults to understand the feelings of loneliness and also expected to control daily internet usage.

\subsection{Paper Structure}

The rest of the paper is organized as follows. Section 2 contains the theories about problematic internet use and loneliness. Section 3 contains methods of this research which are participants and measurement. Section 4 contains the results and discussions about the relationship between loneliness and problematic internet use. Section 5 contains the conclusion about this research.

\section{BACKGROUND}

\subsection{Problematic Internet Use}

PIU is the difficulty that individuals experience in managing life when they are not using the internet which involves emotional symptoms, behavior, as well cognitive (Caplan et al.) [2]. PIU is basically different from the term of internet addiction. PIU explained that excessive internet use is a problem psychosocial and cognitive-behavioral so it has symptoms that belong to non-clinical symptoms and not classified as pathological symptoms, while the internet addiction describes the nature of excessive internet use pathological (Caplan) [12]. Shapira et al. [13] also said that pathology disorder and substance abuse lead to a new disorder than defined PIU itself.

Based on Caplan [12], there are five dimensions of PIU which are preference for online social interaction, mood regulation, cognitive preoccupation, compulsive internet use, and also negative outcomes.

\subsection{Loneliness}

Loneliness itself can be defined states that loneliness can be interpreted as the dynamism of individual personality that determines behavior and patterns thought so that the emergence of individual desires in social life as well later depression may develop (Russell) [14]. Also loneliness can be defined as negative emotions in individuals which comes from an imbalance between social relationships with other people in quantity and quality which is expected with what occurs in the individual's life (Russell, Peplau and Cutrona) [6]. According to Russell [14], loneliness has three aspects, there are personality, social desirability, and depression.
There are two type of loneliness which are emotional loneliness and social loneliness (Weiss in Perlman \& Peplau) [15].

\section{METHOD}

\subsection{Participants}

The study involved 508 participant young adults aged 1840 years consisting of 133 men and 375 women in Indonesia. Participants obtained through online questionnaires. All participants are internet users that use social media and live in Indonesia. Participants in this study it is not limited by race, ethnicity, religion, ethnicity, and culture.

\subsection{Measurement}

Problematic Internet use was measured using the Generalized Problematic Internet Use Scale 2 from Caplan [12] which was arranged by Reinaldo \& Sokang [3]. This scale is using Likert scale consists of 15 statements. This scale consists of eight levels, 1 for strongly disagree (STS) until 8 for strongly agree (SS).

Loneliness was measured using the UCLA Loneliness Scale Version 3 from Russell [14] which arranged by Fatriani [16]. The scale using Likert scale which consists of 11 favorable items (e.g., "How often do you feel alone?") and 9 unfavorable items (e.g., How often do you fed outgoing and friendly?"). There were 4 choices in this scale, Never (TP), Rarely (J), Sometimes (KK), and Always (S).

\section{FINDINGS AND DISCUSSION}

\subsection{Findings}

This study involved $133(26.2 \%)$ men and 375 (73.8\%) women. The age of the participants was in the range of 18 until 40 years. Total participant in the range 18-25 was $429(84.4 \%)$, range $26-33$ was $70(13.8 \%)$, and range $34-40(1.8 \%)$.

The mean hypothetic for variable Problematic Internet Use (PIU) was 4.5. Mean empiric for PIU's first dimension which Preference for Social Online Interaction showed 4.27, dimension Mood Regulation showed 5.43, dimension Cognitive Preoccupation showed 4.68, dimension Compulsive Internet Use showed 4.77, and last dimension Negative Outcomes showed 3.96. Meaning that participant higher in Mood Regulation, Cognitive Preoccupation, Compulsive Internet Use.

PIU in participants divided into categories, performed using the hypothetical statistic. The results obtained 93 (18.3\%) participants with low category, 299 (58.9\%) participants with medium category, and $116(53.9 \%)$ participants with high category. So, most of the participants in this study have medium category of PIU. 
Table 1 Category of Problematic Internet Use

\begin{tabular}{ccc}
\hline Category & Frequency & Percentage \\
\hline Low & 93 & 18.3 \\
Medium & 299 & 58.9 \\
High & 116 & 22.8 \\
\hline Total & 508 & 100
\end{tabular}

Meanwhile, loneliness divided into categories, performed using the hypothetical statistic. The results obtained 32 (6.3\%) participants with low category, 417 (82.1\%) participants with medium category, and 59 (11.6\%) participants with high category. Meaning that most of the participants in this study have loneliness in medium category.

Table 2 Category of Loneliness

\begin{tabular}{ccc}
\hline Category & Frequency & Percentage \\
\hline Low & 32 & 6.3 \\
Medium & 417 & 82.1 \\
High & 59 & 11.6 \\
\hline Total & 508 & 100
\end{tabular}

Normality test with Kolmogorov-Smirnov in PIU showed that $p=0.299$ (>0.05). While, normality test in loneliness showed that $p=0.407$ ( $>0.05)$, means that the data are normally distributed. The presence of normally distributed data shows that analysis for this study's data use a parametric test called Pearson Correlation.

Table 3 Normality Statistics

\begin{tabular}{|c|c|c|}
\hline \multirow{2}{*}{ Variable } & \multicolumn{2}{|c|}{ Kolmogorov-Smirnov } \\
\cline { 2 - 3 } & Sig. $(p)$ & Distribution \\
\hline $\begin{array}{c}\text { Problematic Internet } \\
\text { Use }\end{array}$ & 0.299 & Normal \\
\hline Loneliness & 0.407 & Normal \\
\hline
\end{tabular}

Pearson Correlation results showed that $\mathrm{r}(508)=0.432$ and $p=0.000(<0.05)$, which hypothesis in this study was accepted and meaning that there was a significant and positive relationship between loneliness and problematic internet use.

Table 4 Test of Hypothesis

Loneliness and

Problematic Internet Use

\begin{tabular}{cc}
\hline $\mathrm{r}$ & 0.432 \\
$p$ & 0.000 \\
\hline
\end{tabular}

This study also tested the hypothesis between loneliness and the five dimensions of PIU. Hypothesis test results for loneliness and dimension preference for online social interaction showed that $\mathrm{r}(508)=0.440, p=0.000(<0.05)$. Second, hypothesis test result for loneliness and dimension mood regulation showed $\mathrm{r}(508)=0.375, p=0.000(<0.05)$. Dimension cognitive pre-occupation and loneliness showed hypothesis results $\mathrm{r}(508)=0.239, p=0.000(<0.05)$.
Hypothesis test results for loneliness and dimension compulsive internet use showed that $\mathrm{r}(508)=0.311, p=$ $0.000(<0.05)$. Last, hypothesis test results for loneliness and dimension negative outcomes showed that $\mathrm{r}(508)=$ $0.296, p=0.000(<0.05)$. Means, there were significant and positive relationship between loneliness and all dimensions of PIU.

Table 5 Test of Hypothesis in Dimensions of PIU

\begin{tabular}{ccc}
\hline Table 5 Test of Hypothesis in Dimensions of PIU \\
\cline { 2 - 3 } Dimension & \multicolumn{2}{c}{ Loneliness } \\
\hline Preference for Online Social & 0.440 & 0.000 \\
Interaction & & \\
Mood Regulation & 0.375 & 0.000 \\
Cognitive Pre-Occupation & 0.239 & 0.000 \\
Compulsive Internet Use & 0.311 & 0.000 \\
Negative Outcomes & 0.296 & 0.000 \\
\hline
\end{tabular}

The Levene's test and Independent Sample t-test was conducted to see the differences in loneliness and problematic internet use between participant's gender. In PIU dimension preference for online social interaction, the Levene's test results showed that $\mathrm{F}=0.126, \mathrm{p}=0.723$ (> $0.05)$ and $\mathrm{t}(508)=-1.836, \mathrm{p}=0.067(>0.05)$. Mean rank in men was 4.0150 and mean rank in women was 4.3556 . Meaning there is no significant differences in dimension preference for online social interaction between men and women.

Table 6 Levene's Test and Independent Sample T-test in Dimension Preference for Online Social Interaction Among Gender

\begin{tabular}{cccccc}
\hline Gender & Mean & \multicolumn{2}{c}{ Levene's test } & \multicolumn{2}{c}{$\begin{array}{c}\text { Independent } \\
\text { Sample T-test }\end{array}$} \\
\cline { 3 - 6 } & & F & Sig. & t & Sig. \\
\hline Men & 4.0150 & \multirow{2}{*}{0.126} & 0.723 & 1.836 & 0.067 \\
Women & 4.3556 & & & & \\
\hline
\end{tabular}

Second dimension mood regulation, the Levene's test results showed that $\mathrm{F}=6.106, \mathrm{p}=0.014(<0.05)$ and $\mathrm{t}(508)$ $=-1.624, \mathrm{p}=0.106(>0.05)$. Mean rank in men was 5.2080 and mean rank in women was 5.5111. Meaning there is no significant differences in dimension mood regulation between men and women.

Table 7 Levene's Test and Independent Sample T-test in in Dimension Mood Regulation Among Gender

\begin{tabular}{cccccc}
\hline Gender & Mean & \multicolumn{2}{c}{ Levene's test } & \multicolumn{3}{c}{ Independent } \\
& & & \multicolumn{3}{c}{ Sample T-test } \\
\cline { 3 - 6 } & & $\mathrm{F}$ & Sig. & $\mathrm{t}$ & Sig. \\
\hline Men & 5.2080 & \multirow{2}{*}{6.106} & 0.104 & 1.624 & 0.106 \\
Women & 5.5111 & & & & \\
\hline
\end{tabular}

The Levene's test results in dimension cognitive preoccupation showed that $\mathrm{F}=1.042, \mathrm{p}=0.308(<0.05)$ and $\mathrm{t}(508)=-0.038, \mathrm{p}=0.970(>0.05)$. Mean rank in men was 4.6724 and mean rank in women was 4.6809 . Meaning 
there is no significant differences in dimension cognitive preoccupation between men and women.

Table 8 Levene's Test and Independent Sample T-test in Dimension Cognitive Preoccupation Among Gender

\begin{tabular}{cccccc}
\hline Gender & Mean & \multicolumn{2}{c}{ Levene's test } & \multicolumn{2}{c}{$\begin{array}{c}\text { Independent } \\
\text { Sample T-test }\end{array}$} \\
\cline { 3 - 6 } & & F & Sig. & t & Sig. \\
\hline Men & 4.6724 & \multirow{2}{*}{1.042} & 0.308 & 0.038 & 0.970 \\
Women & 4.6809 & & & & \\
\hline
\end{tabular}

The Levene's test results in dimension compulsive internet use showed that $\mathrm{F}=2.981, \mathrm{p}=0.085(<0.05)$ and $\mathrm{t}(508)=$ $-1.161, p=0.246(>0.05)$. Mean rank in men was 4.6216 and mean rank in women was 4.8267 . Meaning there is no significant differences in dimension compulsive internet use between men and women.

Table 9 Levene's Test and Independent Sample T-test in Dimension Compulsive Internet Use Among Gender

\begin{tabular}{cccccc}
\hline Gender & Mean & \multicolumn{2}{c}{ Levene's test } & \multicolumn{2}{c}{ Independent } \\
& & & \multicolumn{3}{c}{ Sample T-test } \\
\cline { 3 - 6 } & & $\mathrm{F}$ & Sig. & $\mathrm{t}$ & Sig. \\
\hline Men & 4.6216 & \multirow{2}{*}{2.981} & 0.085 & 1.161 & 0.246 \\
Women & 4.8267 & & & & \\
\hline
\end{tabular}

Last dimension which negative outcomes showed Levene's test results $\mathrm{F}=2.642, \mathrm{p}=0.105(<0.05)$ and $\mathrm{t}(508)=$ $1.964, p=0.0501(>0.05)$. Mean rank in men was 3.7218 and mean rank in women was 4.0382 . Meaning there is no significant differences in dimension negative outcomes between men and women.

Table 10 Levene's Test and Independent Sample T-test in Dimension Negative Outcomes Among Gender

\begin{tabular}{|c|c|c|c|c|c|}
\hline \multirow[t]{2}{*}{ Gender } & \multirow[t]{2}{*}{ Mean } & \multicolumn{2}{|c|}{ Levene's test } & \multicolumn{2}{|c|}{$\begin{array}{l}\text { Independent } \\
\text { Sample T-test }\end{array}$} \\
\hline & & $\mathrm{F}$ & Sig. & $\mathrm{t}$ & Sig. \\
\hline Men & 3.7218 & 2642 & 0105 & 1.964 & 0.0501 \\
\hline Women & 4.0382 & & & & \\
\hline
\end{tabular}

The Levene's test and Independent Sample t-test in loneliness showed $\mathrm{F}=2.480, p=0.116$ and $\mathrm{t}(508)=0.280$, $p=0.779$. Mean rank in men was 2.4325 and mean rank in women was 2.4188. Meaning there is no significant differences in loneliness between men and women.

Table 11 Levene's Test and Independent Sample T-test in Dimension Negative Outcomes Among Gender

\begin{tabular}{cccccc}
\hline \multirow{2}{*}{ Gender } & Mean & \multicolumn{2}{c}{ Levene's test } & \multicolumn{3}{c}{$\begin{array}{c}\text { Independent } \\
\text { Sample T-test }\end{array}$} \\
\cline { 3 - 6 } & & F & Sig. & t & Sig. \\
\hline Men & 2.4325 & \multirow{2}{*}{2.480} & 0.116 & 0.280 & 0.779 \\
Women & 2.4188 & & & &
\end{tabular}

\subsection{Discussion}

The results obtained based on this study indicate that there was a significant and positive relationship loneliness with problematic internet use. Means, the higher loneliness in individual, the higher it is problematic internet use in individuals. Vice versa, the lower loneliness, the lower problematic internet use in individuals. This prove that young adults who assume that relationships with other individuals less meaningful in terms of quality and quantity can cause experience high loneliness. The emergence of this feeling of loneliness will make early adults look for other ways to interact socially with other individuals who cannot be owned when doing face-to-face social interactions. One of the ways is to use the internet, namely social media. This is supported by Costa et.al [4] which states that individuals who experiencing loneliness prefers making use of social contact using Internet. The use of the internet especially social media as substitute face-to-face social interaction that can make young adults experiencing problematic internet use. This corresponds to research by Reinaldo \& Sokang [3] which found that young adults with high problematic internet use is an individual use the internet more often than usual to do some social activities such as accessing social media sites.

More detailed relationship between the two variables can be explained through hypothesis test between loneliness and the dimensions of problematic internet use. The dimension of problematic internet use consists of preference for online social interaction, mood regulation, cognitive preoccupation, compulsive internet use, and negative outcomes. Based on the results of the hypothesis test, it was found that loneliness with the five dimensions of problematic internet use has a significant and positive relationship. This means that the higher in individual, the higher the five dimensions of problematic internet use in individual.

This study found that most of the participants in the study it has medium category of loneliness $(82.1 \%)$. Also, some participants in this study have problematic internet use in medium categories $(58.9 \%)$. In the variable of problematic internet use, the dimension with the highest mean empirical when compared to hypothetical mean is mood regulation. This can be interpreted that participants in this study had a high level of mood regulation dimensions. Means, thus young adults in this study use the internet more to reduce unpleasant feelings such as loneliness. This is in agreement with the theory proposed by Muñoz-Rivas et al. [17] that individuals who use the internet excessively make the internet as a reliever of sadness, anxiety, and loneliness rather than individuals who use the internet in a normalized stage.

Furthermore, the additional analysis test in this study was carried out by a differences test based on gender. Differences test on the loneliness variable obtained the result that there is no significant difference between men and women. This results have different results with previous research by Wedaloka \& Turnip [18] which found that there is a significant difference in the level of loneliness 
between men and women. The different results between previous research and this research can occur because of measuring instruments and differences in the target study participants. The difference in loneliness in men and women on previous research can be explained by the theory of De Jong Gierveld et al. [19] that men are more emotionally independent and have no exclusive relationship with other individuals although still dependent on social support from other individuals. Meanwhile, women have more complex affective needs which means that having a relationship with one individual is not enough.

Different tests on the dimensions of the problematic internet use variable get

The results showed that there is no significant differences between men and women in all dimensions of problematic internet use. The results of this study different with previous research conducted by Ergun-Basak \& Aydin [20] who found that men were more problematic internet use in all dimensions than women. The different results between previous research and this research can occur because of measuring instrument and targets participants. The level of problematic internet use in men higher than women in previous studies can be explained by the theory that men prefer and are attracted online activities on the internet and it is easier to find various ways to access the internet (Morahan-Martin \& Schumacher) [21].

The limitation in this study are due to the COVID-19 pandemic, data collection only uses a questionnaire in google form so researchers cannot see directly the seriousness of the participants when fill out the questionnaire and participants cannot ask questions when experiencing difficulties in understanding the items. Researchers also used the loneliness measurement tool that not measuring emotional loneliness and social loneliness deeper in the individual.

\section{CONCLUSIONS}

The conclusions based on the results of this study found that there is significant and positive relationship between loneliness variable and problematic internet use. The positive relationship between the two variables means that the higher loneliness in the individual, the higher problematic internet use in individuals. Likewise, the lower loneliness in individuals, the lower problematic internet use in individuals.

\section{ACKNOWLEDGMENT}

The researcher would like to thank all the participants in this research and the Faculty of Psychology in Universitas Tarumanagara that gives the researcher opportunity to do this research.

\section{REFERENCES}

[1] C. Montag, K. Bey, et al., Is it meaningful to distinguish between generalized and specific internet addiction? Evidence from a cross-cultural study from Germany, Sweden, Taiwan and China, Asia-Pacific Psychiatry: Official Journal of the Pacific Rim College of Psychiatrists 7(1) (2015) 20-26. DOI: 10.1111/appy. $\underline{12122}$

[2] S. Caplan, D. Williams, N. Yee, Problematic Internet use and psychosocial well-being among MMO players, Computers in Human Behavior 25(6) (2009) 1312 1319. DOI: $10.1016 /$ j.chb.2009.06.006

[3] Reinaldo, Y. A. Sokang, Mahasiswa dan internet: Dua sisi mata uang? problematic internet use, Jurnal Psikologi 43(2) (2016) 107-120. DOI: 10.22146/jpsi. $\underline{17276}$

[4] R. M. Costa, I. Patrão, M. Machado, Problematic internet use and feelings of loneliness, International Journal of Psychiatry in Clinical Practice 23(2) (2018) 160-162. DOI: 10.1080/13651501.2018.1539180

[5] S. Turkle, Alone together: Why we expect more from technology and less from each other, Basic Books, 2011.

[6] D. W. Russell, L. A. Peplau, C. E. Cutrona, The revised ucla loneliness scale: Concurrent and discriminant validity evidence, Journal of Personality and Social Psychology 39(3) (1980) 472-480. DOI: $\underline{10.1037 / / 0022-3514.39 .3 .472}$

[7] K. Peltzer, S. Pengpid, Loneliness correlates and associations with health variables in the general population in Indonesia, International Journal of Mental Health Systems 13(1) (2019) 24. DOI: 10.1186/s13033$\underline{019-0281-\mathrm{Z}}$

[8] J. W. Santrock, Life-Span Development (17 $7^{\text {th }}$ ed.), McGraw-Hill Education, 2019.

[9] D. E. Papalia, R. D. Feldman, Experience Human Development (12 $2^{\text {rd }}$ ed.), McGraw-Hill, 2012.

[10] A. Błachnio, A. Przepiorka, W. Boruch, E. Bałakier, Self-presentation styles, privacy, and loneliness as predictors of Facebook use in young people, Personality and Individual Differences 94 (2016) 26-31. DOI: $\underline{10.1016 / j . p a i d .2015 .12 .051}$

[11] E. W. Andangsari, B. Dhowi, Two typology types of loneliness and problematic internet use (PIU): An evidence of indonesian measurement link to your paper 
(SCOPUS), Advanced Science Letters 22 (5) (2016) 1711-1714. DOI: $10.1166 /$ asl.2016.6740

[12] S. E. Caplan, Theory and measurement of generalized problematic internet use: A twostep approach, Computers in Human Behavior 26(5) (2010) 1089-1097. DOI: https://doi.org/10.1016/i.chb.2010.03. $\underline{012}$

[13] N. A. Shapira, M. C. Lessig, et al., Problematic internet use: Proposed classification and diagnostic criteria, Depression and anxiety 17 (2003) 207-216. DOI: $\underline{10.1002 / \text { da. } 10094}$

[14] D. W. Russell, UCLA loneliness scale (version 3): Reliability, validity, and factor structure, Journal of Personality Assessment 66(1) (1996) 20-40. DOI: $\underline{10.1207 / \mathrm{s} 15327752 \mathrm{jpa6601} 2}$

[15] D. Perlman, L. A. Peplau, Loneliness, Encyclopedia of Mental Health 2, Academic Press (1998) 571-581.

[16] D. F. Fatriani, Hubungan dukungan sosial denggan kesepian pada mahasiswa tahun pertama yang merantau di universitas $\mathrm{X}$ jakarta, Thesis, Universitas Tarumanagara, 2019.

[17] M. J. Muñoz-Rivas, L. Fernández, M. GámezGuadix, Analysis of the indicators of pathological internet use in spanish university students, The Spanish Journal of Psychology 13(2) (2010) 697-707. DOI: 10. $\underline{1017 / \mathrm{S} 1138741600002365}$

[18] K. B. Wedaloka, S. S. Turnip, Gender differences in the experience of loneliness among adolescents in Jakarta, Humanitas Indonesian Psychological Journal 16(1) (2019) 33-42.

[19] J. De Jong Gierveld, T. G. Van Tilburg, P. A. Dykstra, Loneliness and social isolation, in A. Vangelisti \& D. Perlman (Eds.), The Cambridge Handbook of Personal Relationships (Cambridge Handbooks in Psychology, 2006, pp. 485-500. DOI: https://doi.org/10. $\underline{1017 / \mathrm{CBO} 9780511606632.027}$

[20] B. Ergun-Basak, M. Aydin, Problematic internet use in term of purposes of internet use, irrational beliefs, feeling of inferiority, and gender, Addicta: The Turkish Journal on Addictions 6(3) (2019) 469-494. DOI: $\underline{10.15805 / \text { addicta.2019.6.3.0017 }}$

[21] J. Morahan-Martin, P. Schumacher, Incidence and correlates of pathological internet use among college students, Computers in Human Behavior 16 (2000) 1329. DOI: https://doi.org/10.1016/S0747-5632(99) 00049-7 